\title{
Leveraging Civic Education as a Strategic Approach in Managing Conflicts among Health Workers in Zambia
}

\author{
Matilda Mambwe, Viola Hamainza, Rachael Simwatachela, Kasonde Mundende, Francis Simui, \& Gistered Muleya \\ University of Zambia
}

\begin{abstract}
The study sought to propose alternative strategies General Nursing Council (GNC) can use in managing conflict among health workers in Zambia. It was a descriptive qualitative design and data was generated using interview guides. Purposive sampling procedure was used to target thirty-eight (38) participants. The data generated was analyzed thematically and the main findings among others were that the General Nursing Council needed to be re-engineered if it were to attend to the needs of the nurses as well as managing the perceived conflicts within and among the groups in the profession; the study further revealed that there was need for the GNC to decentralize its operations across the country so that it can effectively manage the perceived conflicts associated with the nursing profession; the study further noted that peace and conflict related topics could be incorporated into the nurses curriculum in order to equip the researchers and practitioners in the field on the best ways and means of managing conflicts in the nursing profession as well as the health workers alike. The study therefore concludes that the health workers should be informed on the best practices of resolving conflicts that come in the line of their duty and that the GNC should come up with civic education programmes that will support the nurses and other health workers in managing conflicts in the places of work.
\end{abstract}

Keywords: Conflict Management, Civic Education, Alternative Strategies, General Nursing Council, Health workers

\section{INTRODUCTION}

$\mathrm{H}$ ealthcare providers have different values and beliefs and when working together, their greatest challenge is conflict and conflict management. Thus, acknowledging that conflict is a constant issue in healthcare, professionals' reaction to conflict has a great impact on quality patient care (Higazee, 2015). Health workers need to be equipped with conflict management skills because of the complexity of healthcare organizations and for them to effectively deliver the healthcare required.

Not only equipping them with conflict management skills but would also need to be equipped with the core civic education skills not limited to civic skills, civic knowledge, civic values and civic dispositions. As noted by Muleya (2017a; 2017b; 2018a; 2018b; 2018c; 2019); Bergersen \& Muleya (2019); Machila et al (2018); Magasu, Muleya \& Mweemba (2020); Mupeta \& Muleya (2019); Habanyati et al (2020); Mupeta et al (2020); Mwanangombe et al (2020); Mwase et al (2020), Civic Education supports experiences, reflections, assumptions among many others in gaining great understanding through hands-on knowledge on civic issues and actions. Such civic issues and actions are critical components in the management of conflicts in any given community and the health care organisations alike. While civic education is an important ingredient in conflict resolutiuon matters, there seems to be a gap in terms of conflict management skills by the General Nursing Council .Evidently, the realm of healthcare has become increasingly litigious with consumers expecting perfect outcomes at each point of care and for each presenting diagnosis as supported by (Mills, 2002). GNC on the other hand needs to include conflict management as a stand-alone course in their curriculum so that skills are imparted while on training and should be directly involved in the management of conflict among health workers.

Moreover, healthcare providers when working together, especially under pressure, the uniqueness of these professionals results in conflict affecting not just the present situation, but also future decisions of health organizations and includes factors such as; individual characteristics, ambiguous job boundaries, decision making, communication and expectation (Patton, 2012).

Thus, the purpose of the study was to explore the role of the GNC in managing conflict among health workers in Zambia, in selected health facilities of Lusaka District.

\section{METHODOLOGY AND DESIGN}

This study guided by qualitative methodology in nature and adopted a Descriptive design . The study was conducted in Lusaka province and two health facilities were selected namely: HC 1 and HC 2. It involved 38 participants among them included Doctors, nurses, clinical officers, pharmacy personnel, laboratory technicians, nursing managers, nurse tutor and GNC officials. Data collection tools included semistructured questionnaires and interview guides. Data was analyzed thematically where similar responses were categorized into codes, sub themes and themes., which were then presented and discussed.

\section{PRESENTATION OF FINDINGS}

The study objective was to propose alternative strategies GNC can use in managing conflict among health workers in 
Zambia. GNC explained a number of strategies that are in place in order to manage conflict in health institutions. Among the strategies mentioned include; the nurses and midwives Act, NO 31 of 1997, which governs the affairs of nurses and midwives, the professional conduct and disciplinary code of nurses so that they are empowered with management and leadership skills during their training. They conduct trainer of trainers and have the complaints case flow charts and guidelines.

However, a number of alternative strategies were suggested by the participants such as; routine visitations by GNC to health facilities, workshops on conflict management, conflict management as a stand-alone course, decentralization of GNC operations and the complaints case flow chart in health facilities.

One alternative strategy which came out regards the familiarization of GNC in managing conflicts among health workers through routine visitations to health facilities. When the participants were asked to propose alternative strategies, one participant remarked:

"GNC must be visiting health facilities to familiarize themselves with issues on the ground" (Female, RN).

It was established that GNC rarely visited the health facilities to learn and appreciate the experiences health workers go through and as such they was a disjuncture between the health workers and the nursing council Therefore, routine visitations by GNC to health facilities was proposed as an alternative strategy to conflict management among health workers.

Workshops on conflict management were also raised by health workers, especially from nurses.

"There is too much conflict in the health facilities here, so, GNC should be conducting workshops on conflict management so that we know what steps to follow"(Female, $R N)$.

Thus, it is necessary for the workshops to be conducted regularly in order to equip the health workers with the knowledge needed on conflict management.

On conflict management as a stand-alone course, the other participant remarked:

"Health staff must be trained in conflict management adequately while they are in college, so that each and every one is aware of the DO $S$ and DONTS, so the course should be taken seriously on its own"(Female, RM).

It was established from the nurses' perspectives that the nursing curriculum did not incorporate issues of conflict management to a great extent apart from just a small component which was captured $r$ leadership as a topic.

Furthermore, decentralization of GNC operations was also strongly proposed by the participant so that the challenges faced by the nurses and other health workers could be attended to on time.
"If they had offices at District level, it would be better, because for someone far away in the rural areas, it is difficult to lodge in a complaint whenever there is conflict" (Female, $R N)$.

It was evident from the participants that the operations of GNC needed to be decentralized to create efficient ways of addressing of conflict management issues among health workers.

Another alternative strategy was a complaints case flow charts, yet GNC was claiming to have provided the same. When asked about the procedure to follow, some participants noted that:

"We don't know what procedures to follow because, there
are no case flowcharts here" $R N)$.

\section{DISCUSSION OF THE FINDINGS}

GNC, as a regulatory body has put in place strategies such as: Nurses and midwives Act, professional code of conduct, training of trainers and sensitization, but still, conflict is not being managed to the expected standards. The Nurses and midwives Act of 1997 has redefined the functions of the council and expanded the scope of practice for nurses and midwives, where current trends in health care were incorporated in the updated nurses and midwives curricula .Courses such as conflict management have been included in the curricula, though under the change and leadership, which is just a drop in the ocean when it comes to dealing with conflict management among health workers.

Therefore, the study established that the Act has lacunas in terms of conflict management, hence the need to amend it so that conflict management is included. On the other hand, the professional code of conduct is a disciplinary code for nurses and midwives, which spells the DO'S and DONT'S, whenever they are executing their duties but, it was established from the responses of participants that there is not much compliance by nurses and midwives as most of them are not aware of their expected standards, hence, GNC needs to re-orient its members on the content of the code.This is calls for intensified civic education which will help all the parties concerned to understand their civic and social responsibilities in places of work and by so doing it will help in minimizing perceived conflicts at any given time.

While GNC promotes professionalism among practitioners by way of continued professional development (CPD), nurses and other health workers are encouraged to continue updating their knowledge and acquire skills which will equip them to manage conflicts as and when they arise during the course of duty. Shettleworth (2010), observed that; sensitization is a non-associative learning process in which repeated administration of a stimulus results in progressive amplication of a response. It was established that GNC needed to get involved in the sensitization programmes that will help them manage conflicts. In addition, ICTs could be applied to 
harness Civic Education as a mitigatory measure especially given the COVID-19 imposed physical space limitations (Simui, Kasonde Ngandu, Cheyeka and Makoe, 2019; Simui, Mwewa, Chota, Kakana, Mundende, Thompson, Mwanza, Ndhlovu \& Namangala, 2018; and Simui, Nyaruwata and Kasonde-Ngandu, 2017).

Alternative strategies were emphasized such as; decentralization of GNC operations, conflict management as a stand-alone course, complaints case flow charts in health facilities, workshops on conflict management and routine visitations of health facilities by GNC officials. As evidenced from the presentations, there was an outcry from the participants for GNC officials to be visiting health facilities so that they familiarize themselves with the setup of health facilities. Thus, it was established that the health workers need regular visitations by GNC so as to appreciate the challenges that nurses and other health workers go through. Conflict management plays an important role everywhere, at workplaces, and even in our personal lives so as to prevent conflict and workers to concentrate on their work. Thus, leaders should not try to eliminate conflict, but instead, manage differences productively in order to increase efficiency and proficiency.

The study thus established that having workshops fosters a better public perception of the organization's brand and reduces perceived conflicts.. It also improves relationships among health workers, provides creative solutions and lasting agreements, addressing current and future challenges regarding conflict management among health workers. Conflict management as a stand-alone course was another alternative given by the participants especially among the nurses, where it was noted that nursing education was not adequately equipping nurses in conflict management issues.

The findings discussed are in line with Walsh (2002), who found out that educating nurses about conflict was cardinal. Allen (1998), observed that decentralization stimulates the formation of small cohesive groups. Since local managers are given a large degree of authority and local autonomy, they tend to weild their power into closely knit integrated groups. This therefore improves the morale of employees as they get involved in decision making processes. The study therefore established that decentralization includes better, more timely decisions and increased motivation and eases the burden on top management in the end, facilitates diversification and development of lower management so that each manager is responsible for few employees, hence, conflict management is accelerated.

Another alternative strategy from the participants was the issue of the complaints case flowcharts, though GNC's response was that nurses are oriented to the flow chart during induction, but unfortunately, there were no flow charts from the two sampled health facilities. It was established that flow charts help in communicating the steps of a solution to others as it is a graphical representation of the problem solving process. Therefore, GNC should initiate the grievance procedure where investigations have to be instituted, then hold a grievance hearing for natural justice to prevail, then make decisions and inform the health workers of further action.

This study thus revealed that the different disciplines of health workers usually have distinct priorities which arise from the beliefs, backgrounds, knowledge and values associated with individuals and their professions.

As observed from the participants' responses, the study is in agreement with Mills (2002), who observed that when health workers are working together, especially under pressure, the uniqueness of these professionals results in conflict, affects not just the present situation, but also the future decisions of health organizations, as witnessed from the responses, where health workers complained of transferring their grievances on the patients. Furthermore, the study established that service delivery is affected, especially when conflict is not resolved promptly, tension heightens, working environments become unfriendly and reduces the morale, raises burnout, taints the image of the health institution, thereby lowering motivation and performance. Thus, it is important to resolve conflict immediately to avoid taking matters on patients, because at times, patients complain as they could sense the tension among the staff. Conflict if not managed well, has an effect on the patients and as such, GNC should also come up with better strategies to employ so that conflict management is enhanced among the nursing profession and other health workers.

\section{CONCLUSION}

In this article, an attempt has been made to propose the alternative strategies GNC can use in managing conflict among health workers in Zambia. The GNC is not directly involved in managing conflict because it is not an employer of health workers and as such, only comes in to deal with conflict if it involves gross professional misconduct of which, it is a known fact that pro-activity should precede reactivity. Thus, GNC encounters a lot of challenges such as; delayed reporting of conflict cases which leads to delayed justice. However, strategies by GNC to help in professional conduct of nurses have been advanced such as; the nurses and midwives Act of 1997, which acts as the mother Act for the practice of nursing in Zambia. Training of trainers to encourage continued professional development so that skills acquired are transferred to the new nurses. Sensitization to the general public on the functions of GNC, is another strategy but it should also be extended to its members so as to bring harmony to both parties.

\section{RECOMMENDATIONS}

1. Decentralize GNC operations so as to enhance conflict management. There should be GNC officials at District level of health care so that there is quick disposal of cases.

2. There is need for a combined Act of parliament to govern all health workers holistically as the patient is 
the center of health organizations, like the New Zealand model of health quality assurance Act of 2003.

3. GNC on the other hand should facilitate workshops on conflict management at regular intervals for all health workers in the facilities as part of continuous professional development (CPD), and should be an ongoing activity.

4. GNC should introduce conflict management as a stand-alone course in the nurses curriculum so that nurses acquire the necessary skills needed in conflict management, unlike the way it has been structured, where it is a small component in the leadership unit.

\section{REFERENCES}

[1] Allen, G., (1998). 'Changing Conceptions of Local Governance in Public Administration and Development and its predecessors'. In Journal of Public Administration and Development, vol. 19, NO. 5, pp. 439-452.

[2] Bergersen, A. and Muleya, G. (2019). Zambian Civic Education Teacher Students in Norway for a Year- How DoThey Describe Their Transformative Learning? Sustainability 2019, 11 (24), 7143; doi: 10.3390/su11247143, pp $1-17$ www.mdpi.com/journal/sustainability

[3] Clara Mwanangombe, Kasonde Mundende, Kenneth K. Muzata, Gistered Muleya, Vincent Kanyamuna, Francis Simui (2020), Peeping into the Pot of Contraceptives Utilization among Adolescents within a Conservative Culture Zambia American Journal of Educational Research, 2020, Vol. 8, No. 8, 513-523 Available online at http://pubs.sciepub.com/education/8/8/1 Published by Science and Education Publishing DOI:10.12691/education-8-8-1

[4] Daliso Mwase, Eunifridah Simuyaba, Godfrey Mwewa, Gistered Muleya \& Francis Simui (2020), Leveraging Parental Involvement in the Education of their Children as a Conflict Resolution Strategy in Selected Secondary schools, Zambia , International Journal of Research and Innovation in Social Science (IJRISS) |Volume IV, Issue VII, July 2020|ISSN 2454-6186

[5] Habanyati, H., Simui, F., Kanyamuna, V., \& Muleya, G. (2020) Lived Experiences of Multi-Banked Bank Account Holders with a focus on Banks at Manda Hill Mall Lusaka, Zambia. Advances in Social Sciences Research Journal, 7(6) 208-223.

[6] Higazee, M. (2015). 'Types and Levels of conflict experienced by Nurses in the Hospital settings'. In Health Science Journal, vol. 9, NO. 6, pp. 1-7.

[7] Hrinkanic, J. (1998). 'Negotiation: A skill for Nurses'. In the Canadian Nurse Journal, vol. 94, NO. 10, pp. 36-39.

[8] Machila,N, Sompa, M, Muleya, G and Pitsoe, V.J (2018). 'Teachers' Understanding and Attitudes Towards Inductive and Deductive Approaches to Teaching Social Sciences," Multidisciplinary Journal of Language and Social Sciences Education, (2), 120-137. 2018
[9] Magasu, O., Muleya, G. \& Mweemba, L. (2020). Pedagogical Challenges in Teaching Civic Education in Secondary Schools in Zambia. International Journal of Science and Research (IJSR). Vol. 9, Issue 3, pp. 1483-1488. DOI: 10:21274/SR 20327121153.

[10] Mills, E.M. (2002). 'Conflict in Healthcare Organizations'. In Journal of Healthcare, Law and Policy, vol.5, NO. 2, pp. 8-23.

[11] Muleya, G. (2017a). 'The Conceptual Challenges in the Conceptualization of Civic Education'. In Journal of Lexicography and Terminology. Vol 1, Issue 1, pp 59-81

[12] Muleya, G. (2017b). 'Civic education and Civics: Where do we draw the line?' In Journal of Lexicography and Terminology. Vol 1 , Issue 2, pp 125-148.

[13] Muleya, G. (2018b). 'Civic Education Versus Citizenship Education? Where is the point of Convergence?' Journal ofLexicography and Terminology, Vol 2, Issue No. 1, pp 109-130.

[14] Muleya, G. (2018a). Civic education in Zambia before and beyond the Golden Jubilee. In G. Masaiti (Ed.), Educationat fifty years of Independence and beyond. Lusaka: Unza Press.

[15] Muleya, G.(2018c). Re-Examining the Concept of Civic Education. Journal of Lexicography and Terminology, Vol 2, Issue No. 2, pp 25- 42.

[16] Muleya, G. (2019). Curriculum Policy and Practice of Civic Education in Zambia: A Reflective Perspective, In A.Petersen et al. (eds.). The Palgrave Handbook of Citizenship and Education. https://doi/10.007/978-3-319-67905-153-1

[17] Mupeta, S., Muleya, G., Kanyamuna, V., \& Simui, F. (2020). Civic Entrepreneurship: The Implementation of Civic Innovations in the Governance of the University of Zambia. Advances in Social Sciences Research Journal, 7(7) 674-685.

[18] Mupeta, S and Muleya, G. (2019). Challenges and Strategies in the Implementation of Civic Entrepreneurship in the Governance of the University of Zambia, In International Journal of Research and Innovation in Social Science (IJRISS) |Volume III, Issue VII, July 2019|ISSN 2454-6186, pp 94 -100.

[19] Patton, C.M. (2014). "Conflict in Healthcare: A Literature Review'. In Journal of Healthcare Administration, vol. 9, NO. 1, pp. $125-131$.

[20] Shettleworth, S.J. (2010). Cognition, Evolution and behavior. (2nd edition). Oxford: Oxford University Press.

[21] Simui, F., Kasonde Ngandu, S., Cheyeka, A.M., and Makoe, M., (2019). Lived Disablers to Academic Success of the Visually Impaired at the University of Zambia. Sub Saharan Africa. Journal of Student Affairs in Africa 7(2), 41-56. https://doi.org/10.24085/jsaa.v7i2.3824

[22] Simui, F., Mwewa, G., Chota, A., Kakana, F., Mundende, K., Thompson, L., Mwanza, P., Ndhlovu, D., \& Namangala, B., (2018). "WhatsApp" as a Learner Support tool for distance education: Implications for Policy and Practice at University of Zambia. Zambia ICT Journal, 2, (2), 36-44, https://doi.org/10.33260/zictjournal.v2i2.55.

[23] Simui, F., Nyaruwata, L.T. and Kasonde-Ngandu, S. (2017). ICT as an Enabler to Academic Success of Students with Visually Impaired at Sim University: Hermeneutics Approach. Zambia ICT Journal Vol. 1. Issue $1.0 \mathrm{pp} 5$ - 9. http://ictjournal.icict.org.zm/index.php/zictjournal/article/view/9

[24] Walsh, M.C. (2002). 'Measures of Psychological Preferences'. In Journal of Psychology, vol. 12, NO. 4, pp. 33-35. 